\title{
Genetic screening in Iranian patients with retinoblastoma
}

Department of Ophthalmology and Eye Research Center, Rassoul Akram Hospital, Iran University of Medical Sciences (IUMS), Tehran, Iran

${ }^{2}$ Reproductive Biotechnology Research Center, Avicenna Research Institute, Tehran, Iran

${ }^{3} \mathrm{NIH}$ Undiagnosed Diseases Program, Common Fund, Office of the Clinical Director, NHGRI, National Institutes of Health, Bethesda, MD, USA

${ }^{4}$ Department of Pediatrics, Rassou Akram Hospital, Iran University of Medical Sciences (IUMS), Tehran, Iran

${ }^{5}$ Department of Pediatrics, Ali Asghar Children Hospital, Iran University of Medical Sciences (IUMS), Tehran, Iran

'Department of Molecular Genetics, National Institute of Genetic Engineering and Biotechnology (NIGEB), Tehran, Iran

${ }^{7}$ Department of Medical Genetics and Molecular Biology, Faculty of Medicine, Iran University of Medical Sciences (IUMS) Biology,

Faculty of Medicine, Iran University of Medical Sciences (IUMS),

Tehran, Iran

Correspondence: B Behnam, NIH Correspondence: B Behnam, NIH Undiagnosed Diseases Program,
National Human Genome Research Institute, NHGRI, National Institute of Health $(\mathrm{NIH})$, Bethesda, MD 20892, USA

Tel: 3015945182

Fax: 3014800804

E-mail: Babak Behnam@ih gov or

b behnam@yahoo.com

${ }^{8}$ Present address: NIH Undiagnosed Diseases Program, Common Fund, Office of the Clinical Director, NHGRI, National Institutes of Health, Bethesda, MD, USA.

${ }^{9}$ Present address: Department of Ophthalmology, Alzahra Eye Hospital, Zahedan University of Medical Sciences, Zahedan, Iran.

${ }^{10}$ These authors contributed equally to this work.

Received: 7 September 2015 Accepted in revised form: 14 Accepted in revised
November 2016 November 2016
Published online: 16 December 2016

\begin{abstract}
Purpose The most common intraocular tumor in childhood, retinoblastoma, is largely associated with mutations in the $R B 1$ gene. In the most comprehensive RB1 screening in Iran, we evaluated the $R B 1$ mutations in 106 patients with retinoblastoma, including 73 bilateral (heritable) and 33 unilateral (sporadic) cases. Patients and methods Mutations were identified using amplification refractory mutation system (ARMS) PCR and direct sequencing of the 27 coding exons of $R B 1$ and multiplex ligation-dependent probe amplification (MLPA).
\end{abstract}

Results and Conclusion We found 33 (31\%) and $64(60 \%)$ patients with sporadic unilateral and bilateral retinoblastoma, respectively as well as $9(\mathbf{8 . 5} \%)$ cases with hereditary bilateral retinoblastoma. In total, we identified 52 causative $R B 1$ mutations in 106 patients (global mutation rate of $49 \%$ ). Of the 52 patients, 48 $(92 \%)$ had sporadic and familial bilateral and 4 (8\%) had sporadic unilateral RB. Therefore, the detection rate of $R B 1$ mutations was $66 \%$ $(48 / 73)$ and $12 \%(4 / 33)$ in bilateral and unilateral cases, respectively. Mutations were classified as nonsense in $31(60 \%)$, missense in $1(2 \%)$, large deletion in $11(21 \%)$, small deletion in the 7 novel (15\%) and splice site mutation in $2(4 \%)$ patients with $\mathrm{RB}$. Of 31 nonsense mutations, $23(74 \%)$ occurred in the 11 Arginine codons of the $R B 1$. Seven mutations (13\%) were novel, and $45(87 \%)$ had been previously reported. Thirty-three mutations were single-base substitutions leading to 31 nonsense amino acid changes and 2 splice site mutations in introns 12 and 16 of RB1. The altered 3D model structures of the RB1 novel mutant proteins are also predicted in this study. Eye (2017) 31, 620-627; doi:10.1038/eye.2016.289; published online 16 December 2016

\section{Introduction}

Retinoblastoma (RB, OMIM 180200) is the most common pediatrics intraocular tumor, derived
K Shahraki 1,9,10, A Ahani2,10, P Sharma ${ }^{3}$, M Faranoush4, G Bahoush ${ }^{5}$, I Torktaz ${ }^{6}$, WA Gahl ${ }^{3}$, M Naseripour ${ }^{1}$ and B Behnam ${ }^{3,7,8}$

from neural retinal germ cells, ${ }^{1}$ and largely caused by $R B 1$ mutations. The annual incidence and occurrence of retinoblastoma varies from 10-14 per million under 5 years of age ${ }^{2}$ to $1: 15000-1: 20000$ live births with no sex predominance. Worldwide, $40 \%$ of RB cases are heritable, mostly associated with bilateral disease; the mean age at diagnosis is 18 months. ${ }^{3}$ Although mutations in both alleles are necessary for $\mathrm{RB}$, the predisposition to develop the disease in familial cases is inherited in an autosomal dominant pattern. ${ }^{4}$ A germline RB1 mutation predisposes patients (with penetrance $\geq 90 \%$ ) to 'multifocal bilateral heritable RB' within the first two years of life as well as secondary tumors like 'bone and connective tissue tumors' later in adulthood. 5,6 The germline mutation is either inherited de novo (acquired via gametogenesis during gestation) or classically inherited from an involved parent. ${ }^{4,7}$ Somatic RB accounts for $\sim 60 \%$ of cases and does not increase a patient's risk of second cancers. In unilateral cases, biallelic $R B 1$ mutations in a single retinal cell lead to RB formation. $1,8,9$

Depending on screening techniques and inclusion criteria for patient selection, a wide range of detection rates (5.5-94.8\%) has been reported for highly heterogenous mutations in the 27 coding exons and the promoter of RB1. ${ }^{10-17}$ Though loss of RB1 function is the initiating event, the most common $R B 1$ alterations leading to $\mathrm{RB}$ are nonsense and single-base mutations. Some genetic RB modifiers, (eg, MDM2), have been recently found to be regulators of disease severity. ${ }^{18-20}$

In this study, we analyzed the RB1 open reading frame (27 exons) in an Iranian retinoblastoma cohort to identify the pattern of scattered mutations and to provide efficient genetic counseling. Since alterations in protein structure lead to altered function, we also predicted the 3D structures of novel RB1 mutant proteins. In this study, most known mutations and all the novel ones produced a truncated RB1 protein that could have reduced or absent function. Since the RB1 protein resembles several 
proteins with known crystallography structures in the protein database (pdb), we used fold recognition to predict the structure of certain parts of RB1. Although a limited number of retinoblastoma patients and their mutations has been previously reported by this group, ${ }^{21-23}$ the current study represents the most comprehensive report of RB1 mutation in Iranian patients with retinoblastoma.

\section{Materials and methods}

\section{Patients}

Of 106 unrelated RB cases recruited between November 2009 and August 2013, 74 had bilateral disease. Of these, 72 had no family history and two were familial cases. In addition, 34 patients had unilateral RB without a positive family history. For the 49 girls and 57 boys, the age at diagnosis ranged from 2.5 to 120 months. All patients were examined and treated at the ophthalmology department of the Rassoul Akram University Hospital, IUMS, Tehran. Detailed demographic data including sex, age, laterality, age at diagnosis, presenting signs and familial history of $\mathrm{Rb}$, were collected. Comprehensive fundus examination and fundus photography by Ret Cam (Massie industries, Dublin, CA, USA) was performed under general anesthesia for each patient. Blood samples $(5 \mathrm{ml})$ were obtained in standard EDTA collection tubes from patients and available relatives. The samples were coded and stored at $-20^{\circ} \mathrm{C}$ until nucleic acid extraction was performed. In accordance with the Declaration of Helsinki, the study was approved by Ethical Committee of Eye Research Center (IUMS), and a written consent for genetic analysis was obtained from parents or legal guardians.

\section{Molecular analysis}

DNA was extracted from peripheral blood using the salting out method. ${ }^{24}$ Screening of $R B 1$ mutations was performed by initial ARMS, multiplex ligation-dependent probe amplification (MLPA) (MRC-Holland, Netherland), followed by PCR-directed sequencing of the 27 coding exons and their flanking intronic regions, using the primers indicated in Table 1..$^{21,22,25} \mathrm{PCR}$ reactions were performed in a thermal cycler (Eppendorf, Hauppauge, NY, USA), in a total volume of $25 \mu$ l containing 100-200 ng of genomic DNA and 5 picomoles of each primer, using Maxime PCR Premix Kit (iNtRON BIOTECHNOLOGY, South Korea). Reactions were performed for 35 cycles of $94^{\circ} \mathrm{C}$ for $1 \mathrm{~min}$, annealing at the specific temperature for $1 \mathrm{~min}$, extension time of $72{ }^{\circ} \mathrm{C}$ for $1 \mathrm{~min}$, and a final extension step at $68^{\circ} \mathrm{C}$ for $7 \mathrm{~min}$. After the unincorporated dNTPs and primers were removed using Exonuclease I, the PCR products were directly sequenced using the ABI BigDye Terminator and
Table 1 List and sequences of the primers used for RB1 exons

\begin{tabular}{|c|c|}
\hline & Sequence $\left(5->3^{\prime}\right)$ \\
\hline RB1F & TTTTGTAACGGGAGTCGGG \\
\hline RB1R & CATTCTGCAGACGCTCCG \\
\hline RB2F & TGTTATGTGCAAACTATTGAAACAAG \\
\hline RB2R & AGGTAAATTTCCTCTGGGTAATG \\
\hline RB3F & TGCCATCAGAAGGATGTGTTAC \\
\hline RB3R & TGGCAGTTCACTATTTGGTCC \\
\hline RB4F & TGTAGAGCTGATAATCTTTTGAATTG \\
\hline RB4R & AATTCCCAGAATCTAATTGTGAAC \\
\hline RB5F & TTGGGAAAATCTACTTGAACTTTG \\
\hline RB5R & CACAGGACTTAAATCTATGGGC \\
\hline RB6F & TCTGGAAAACTTTCTTTCAGTGATAC \\
\hline RB6R & TGGGGAATTTAGTCCAAAGG \\
\hline RB7F & TCTACCCTGCGATTTTCTCTC \\
\hline RB7R & CCACTAGACATTCAATAAGCAACTG \\
\hline RB8F & CAGAGTAGAAGAGGGATGGC \\
\hline RB8R & GGGAGAACTTACATCTAAATCTAC \\
\hline RB9F & TTACCCTGCATTGTTCAAGAGTC \\
\hline RB9R & CTTGGCTAGATTCTTCTTGGGC \\
\hline RB10F & ATTGCATGCGAACTCAGTGT \\
\hline RB10R & TCTACCTATATCAGTATCAACCT \\
\hline RB11F & ATTTTCAGTATGTGAATGACTTC \\
\hline RB11R & ATCTGAAACACTATAAAGCCATGA \\
\hline RB12F & GGAGGCAGTGTATTTGAAGA \\
\hline RB12R & GGATAACTACATGTTAGATAGGAGA \\
\hline RB13F & CTGATTACACAGTATCCTCGAC \\
\hline RB13R & TTATACGAACTGGAAAGATGCTGC \\
\hline RB14-16F & CCCAGGAGTGTGAAGGCCA \\
\hline RB14-16R & TCTCCCCCGACCAAAGAAAC \\
\hline RB17F & TGTTTTCTTTGTCTGATAATAACTTCC \\
\hline RB17R & TTCCСTATATGTTCTTGAGGTAGATG \\
\hline RB18F & GCCACTGTCAATTGTGCCTA \\
\hline RB18R & ATGCAAATCCTAGGTGATTCAG \\
\hline RB19F & TGTATGTATAATCTGTGATTCTTAGCC \\
\hline RB19R & CATGATTTGAACCCAGTCAGC \\
\hline RB21F & TTTGTTCTTTAAACACACTTTGGG \\
\hline RB21R & САТААТТАСССТТАТСТТТССААТТС \\
\hline RB22-23F & CTTTATAATATGTGCTTCTTACCAG \\
\hline RB22-23R & ATTCTTGGATCAAAATAATCCCC \\
\hline RB24F & TCATCTCTGCAAAATTGTATATGG \\
\hline RB24R & AGGTGTTTGAATAACTGCATTTGG \\
\hline RB27F & CAGCCACTTGCCAACTTACC \\
\hline RB27R & CAGTCACATCTGTGAGAGACAATG \\
\hline
\end{tabular}

run on an ABI 3130 Genetic Analyzer. The sequence data were analyzed by comparison to the consensus sequence of the RB1 gene (GenBank L11910.1) using Chromas software (South Brisbane, QLD, Australia). Additional information about mutations and variants was obtained from the GenBank database.

\section{Structure prediction of RB1 mutant proteins}

Since all the novel mutations in this study were frameshifts, a combination of fold recognition and hidden markov model based methods was used to predict the 3D structures/models of the native and mutant RB1 proteins. Therefore, phyre $2^{26,27}$ a fold recognition algorithm and 
SAM-T08 ${ }^{28}$ an HMM based algorithm were used. During these processes, 3D structures were predicted by the multi-templates method. Finally, a Meta prediction following rigid body assembly and energy minimization was performed using Modeller V 9.12 software, ${ }^{29}$ and the minimized structures presented.

\section{Results}

The mean follow-up time for the RB patients in this study was $27.6 \pm 19.2$ months (6-138 months). The mean age at the time of diagnosis was $12.7 \pm 10.5$ and $22.1 \pm 19.6$ months for RB with and without a family history, respectively; these ages are not significantly different. The most common presenting sign was leukocoria and strabismus, in 65.9 and $17.7 \%$ of cases, respectively (Table 2 ).

We enrolled 106 patients with retinoblastoma for $R B 1$ germline mutation detection in this study. Clinically heritable disease occurred in 9 patients with and 64 without a history of bilateral involvement. The other 33 (31.1\%) unilateral cases were classified as sporadic. The mean age at diagnosis was $19.2 \pm 18.3$ months for bilateral patients and $24.0 \pm 17.3$ months for unilateral cases. In total, we identified 38 different causative $R B 1$ mutations in 52 of 106 patients (global mutation detection rate of $49.1 \%$; Table 2). The detection rate of $R B 1$ mutations was $65.8 \%(48 / 73)$ in bilateral/heritable, and $12.1 \%(4 / 33)$ in sporadic unilateral cases. Seven mutations (13.5\%) were novel, and 45 (86.5\%) had been previously reported (RB1 gene database). The novel mutations included: c.755delC (p.Thr252AsnfsX16), c.862delG (p.Val288rmfsX1), heterozygous c.1195_1202delAAATCTGA (p.E398D; fsX4), heterozygous c.1535_1536delTT (p.Leu512V;fsX8), c.1703delC (p.Pro568LeufsX42), c.1831delA (p.Arg611AspfsX11), c.1887_1888delGA (p.Glu629AspfsX22). The 52 patients with detected mutations showed 31 single-base substitutions leading to 28 nonsense (eg p.R251X, p.R255X, p.R320X, p.R358X, p.R579X, p.R787X, p.S320X, p.Q344X, p.S443X, p.Q62X), 1 missense (R661W) amino acid change, and 2 splice site mutations (c.1499-2A > C, c.1216+1G > A) in introns 12

Table 2 The frequency of major complaints of RB patients in this study

\begin{tabular}{lcc}
\hline Symptom/major complaint & Frequency & Percent \\
\hline Leukocoria & 70 & 66 \\
Strabismus & 18 & 17 \\
Red eye & 7 & 6.6 \\
Proptosis, cellulitis,.. & 5 & 4.7 \\
FH+(EUA) & & 5.7 \\
Total & 106 & 100 \\
\hline
\end{tabular}

apatients with positive family history and diagnosed under anesthesia. and 16. Of 31 point mutations, 23 occurred in the 11 arginine codons of $R B 1$ gene, resulted in 22 stop codons $(\mathrm{R} \rightarrow \mathrm{X})$ and 1 missense mutation $(\mathrm{R} 661 \mathrm{~W})$, respectively. The 19 other mutations were small deletions of one or two base pairs causing a frameshift and premature termination (eg p.Arg611AspfsX11, p.Thr252AsnfsX16, p.Pro568LeufsX42) of the open reading frame. All mutations are summarized in Table 3. The analysis of the splice site mutations (c.1499-2A > C;g.70330G > A, c.1216 $+1 \mathrm{G}>$ A;g.78081A > C) with Human Splicing Finder software revealed the consensus value of the wild-type splice acceptor site was decreased by $96 \%$, suggesting a complete disruption of the normal splicing event. In genetic analysis of bilateral familial RB, three out of four cases (\#152, \#172, and \#182) showed the same causative mutations (c.1831delA, c.C1147T, and c.689C > A, respectively) in their sibs/parents, but no common mutation was found in the fourth one (\#187) or any sibs.

\section{Mutant RB1 proteins models}

Nonsense-mediated decay likely has a more significant role in determining the phenotype than mis-folded truncated protein in novel frameshift mutations. However, to compare them together, the 3D structures/models of the native and mutant RB1 proteins were predicted utilizing a combination of phyre2, hidden markov, and SAM-T08 algorithms (Figure 1). Predicted structures were also assessed by Prosa Z-score (Table 4) to evaluate the effects of the identified mutations. The more negative the Z-scores, the more quality and less error in model prediction. The accuracy of computational results in predicting the protein structure by Prosa Z-score, was also evaluated. As the result, an equal quality to NMR and X-ray crystallography models of the wild and dysfunctional mutant forms of the RB1 protein has been detected (Figure 2). The exon 16 mutation, p.L512VfsX8, showed the most similarity to the wild-type RB1 protein (Figures $1 \mathrm{~d}$ and $2 \mathrm{~d}$ ); the novel mutations in exons 18 and 19 showed much less similarity.

\section{Discussion}

This is the most comprehensive report of RB1 mutations in Iranian patients with retinoblastoma, using ARMS, MLPA, and direct sequencing of 27 exons of $R B 1$ gene. The patients were referred to the clinic of genetic ophthalmology during a period of 2.5 years. In this study, we found a trend for the bilateral and unilateral retinoblastoma patients. The number of bilateral cases were much more than the unilateral ones (the ratio for bilateral/unilateral cases is more than $2: 1$ ). While the frequency of distribution of retinoblastoma might partly contribute to higher bilateral/unilateral ratio, this is mainly because the ophthalmology department in Rasoul Akram 
Table 3 Retinoblastoma patients with detected RB1 mutations

\begin{tabular}{|c|c|c|c|c|c|c|}
\hline No & code & Protein & $D N A$ & $c D N A$ & Exon/Intron & laterality \\
\hline \multicolumn{7}{|c|}{ Deletions (Large (6 single exon, 5 whole RB1 gene) and 7 small site nucleotide numbers) } \\
\hline 1 & 11 & Exon 2 deletion & & & 2 & Bilateral \\
\hline 2 & 21 & Exon 2 deletion & & & 2 & Unilateral \\
\hline 3 & 10 & Exon 7 deletion & & & 7 & Bilateral \\
\hline 4 & 194 & Exon 17 deletion & & & 17 & Bilateral \\
\hline 5 & 159 & Exon 19 deletion & & & 19 & Bilateral \\
\hline 6 & 179 & Exon 19 deletion & & & 19 & Bilateral \\
\hline 7 & 3 & Whole gene deletior & & & & Bilateral \\
\hline 8 & 34 & Whole gene deletior & & & & Bilateral \\
\hline 9 & 120 & Whole gene deletior & & & & Bilateral \\
\hline 10 & 139 & Whole gene deletior & & & & Bilateral \\
\hline 11 & 158 & Whole gene deletior & & & & Unilateral \\
\hline 12 & 167 & p.Thr252AsnfsX16 & g.59687delC & c.755delC & 8 & Bilateral \\
\hline 13 & 26 & p.Val288rmfsX1 & g.61730delG & c. $862 \mathrm{delG}$ & 9 & Bilateral \\
\hline 14 & 45 & p.E398D;fsX4 (Hete & fote) c.1195_1202delAAA & & 12 & Unilateral \\
\hline 15 & 49 & p.Leu512V;fsX8 (He & ygote) c.1535_1536del TT & & 16 & Unilateral \\
\hline 16 & 174 & p.Pro568LeufsX42 & g.150005delC & c.1703delC & 18 & Bilateral \\
\hline 17 & 152 & p.Arg611AspfsX11 & g.153224delA & c.1831delA & 19 & Bilateral \\
\hline 18 & 33 & p.Glu629AspfsX22 & g.153280_153281delGA & c.1887_1888delGA & 19 & Bilateral \\
\hline \multicolumn{7}{|c|}{ (31 Nonsense, 1 missense, 2 Intron) Mutations } \\
\hline 19 & 153 & p.Q62X & g. $5470 \mathrm{C}>\mathrm{T}$ & c. $184 \mathrm{C}>\mathrm{T}$ & 2 & Bilateral \\
\hline 20 & 13 & p.L158X & g.42018T > A & c. $473 \mathrm{~T}>\mathrm{A}$ & 4 & Bilateral \\
\hline 21 & 32 & p.Q166X & g.42041G > T & c. $496 \mathrm{G}>\mathrm{T}$ & 4 & Bilateral \\
\hline 22 & 182 & p.S230X & g. $56935 \mathrm{C}>\mathrm{A}$ & c. $689 \mathrm{C}>\mathrm{A}$ & 7 & Bilateral \\
\hline 23 & 2 & p.R251X & g. $59683 C>\mathrm{T}$ & c. $751 C>\mathrm{T}$ & 8 & Bilateral \\
\hline 24 & 197 & p.R251X & g. $59683 C>\mathrm{T}$ & c. $751 \mathrm{C}>\mathrm{T}$ & 8 & Bilateral \\
\hline 25 & 30 & p.R255X & g. $59695 C>T$ & c. $763 \mathrm{C}>\mathrm{T}$ & 8 & Bilateral \\
\hline 26 & 4 & p.R320X & g. $64348 \mathrm{C}>\mathrm{T}$ & c. $958 \mathrm{C}>\mathrm{T}$ & 10 & Bilateral \\
\hline 27 & 40 & p.R320X & g. $64348 \mathrm{C}>\mathrm{T}$ & c. $958 \mathrm{C}>\mathrm{T}$ & 10 & Bilateral \\
\hline 28 & 58 & p.R320X & g. $64348 \mathrm{C}>\mathrm{T}$ & c. $958 \mathrm{C}>\mathrm{T}$ & 10 & Bilateral \\
\hline 29 & 178 & p.R320X & g. $64348 \mathrm{C}>\mathrm{T}$ & c. $958 \mathrm{C}>\mathrm{T}$ & 10 & Bilateral \\
\hline 30 & 198 & p.Q344X & g. $64420 \mathrm{C}>\mathrm{T}$ & c. $1030 \mathrm{C}>\mathrm{T}$ & 10 & Bilateral \\
\hline 31 & 22 & p.R358X & g. $65386 \mathrm{C}>\mathrm{T}$ & c. $1072 \mathrm{C}>\mathrm{T}$ & 11 & Bilateral \\
\hline 32 & 165 & p.R358X & g. $65386 \mathrm{C}>\mathrm{T}$ & c. $1072 \mathrm{C}>\mathrm{T}$ & 11 & Bilateral \\
\hline 33 & 172 & p.Q383X & g.70261C > T & c.C1147T & 12 & Bilateral \\
\hline 34 & 149 & IVS12+1G > T & g.70330G > A & c. $1216+1 G>A$ & Intron 12 & Bilateral \\
\hline 35 & 121 & p.S443X & g.73865C > A & c. $1328 \mathrm{C}>\mathrm{A}$ & 13 & Bilateral \\
\hline 36 & 23 & p.R445X & g.76430C $>\mathrm{T}$ & c. $1333 \mathrm{C}>\mathrm{T}$ & 14 & Bilateral \\
\hline 37 & 138 & p.R445X & g.76430C $>\mathrm{T}$ & c. $1333 \mathrm{C}>\mathrm{T}$ & 14 & Bilateral \\
\hline 38 & 189 & p.R445X & g.76430C $>\mathrm{T}$ & c. $1333 \mathrm{C}>\mathrm{T}$ & 14 & Bilateral \\
\hline 39 & 52 & p.R455X & g.76460C $>\mathrm{T}$ & c. $1363 C>\mathrm{T}$ & 14 & Bilateral \\
\hline 40 & 140 & p.R467X & g.76898C $>\mathrm{T}$ & c. $1399 \mathrm{C}>\mathrm{T}$ & 15 & Bilateral \\
\hline 41 & 17 & p.R467X & g.76898C > T & c. $1399 \mathrm{C}>\mathrm{T}$ & 15 & Bilateral \\
\hline 42 & 25 & p.R467X & g.76898C > T & c. $1399 \mathrm{C}>\mathrm{T}$ & 15 & Bilateral \\
\hline 43 & 27 & IVS16 & g.78081A >C & c. $1499-2 \mathrm{~A}>\mathrm{C}$ & Intron 16 & Bilateral \\
\hline 44 & 80 & p.R556X & g.78250C > T & c. $1666 \mathrm{C}>\mathrm{T}$ & 17 & Bilateral \\
\hline 45 & 193 & p.R579X & g. $150037 C>T$ & c. $1735 \mathrm{C}>\mathrm{T}$ & 18 & Bilateral \\
\hline 46 & 18 & p.Q631X & g. $153284 C>T$ & c. $1891 \mathrm{C}>\mathrm{T}$ & 19 & Bilateral \\
\hline 47 & 15 & p.R661W & g. $156713 C>\mathrm{T}$ & c. $1981 C>$ T & 20 & Bilateral \\
\hline 48 & 12 & p.Y728X & g. $160807 C>G$ & c. $2184 \mathrm{C}>\mathrm{G}$ & 21 & Bilateral \\
\hline 49 & 6 & p.R787X & g. $162237 \mathrm{C}>\mathrm{T}$ & c. $2359 \mathrm{C}>\mathrm{T}$ & 23 & Bilateral \\
\hline 50 & 24 & p.R787X & g. $162237 \mathrm{C}>\mathrm{T}$ & c. $2359 \mathrm{C}>\mathrm{T}$ & 23 & Bilateral \\
\hline 51 & 177 & p.R787X & g. $162237 \mathrm{C}>\mathrm{T}$ & c. $2359 \mathrm{C}>\mathrm{T}$ & 23 & Bilateral \\
\hline 52 & 184 & p.R787X & g. $162237 \mathrm{C}>\mathrm{T}$ & c. $2359 \mathrm{C}>\mathrm{T}$ & 23 & Bilateral \\
\hline
\end{tabular}

Hospital has been the primary referral center (among 2 centers) for the treatment and study of retinoblastoma and also the RB1 genetic study has been offered to patients there as the only and unique center in Iran. Therefore, all ophthalmologists in the country used to refer only their 'bilateral retinoblastoma' to this center.

The screening of 106 patients identified 38 different germline mutations in 52 cases. Our overall mutation 

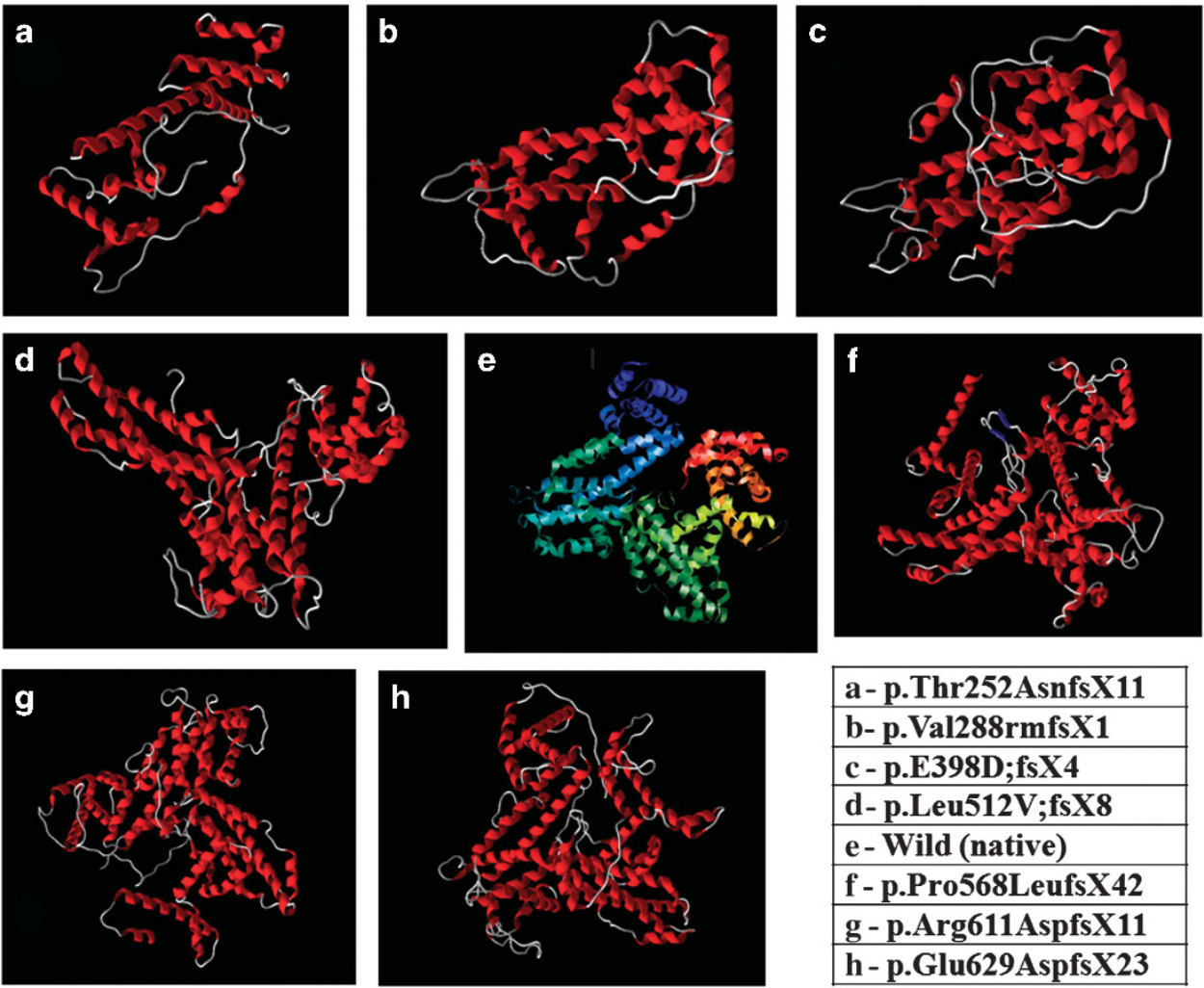

\begin{tabular}{|l|}
\hline a-p.Thr252AsnfsX11 \\
\hline b- p.Val288rmfsX1 \\
\hline c - p.E398D;fsX4 \\
\hline d-p.Leu512V;fsX8 \\
\hline e-Wild (native) \\
\hline f - p.Pro568LeufsX42 \\
\hline g - p.Arg611AspfsX11 \\
\hline h-p.Glu629AspfsX23 \\
\hline
\end{tabular}

Figure 1 Predicted 3D structure models of the RB1 wild (e) and novel mutant (a, b, c, d, f, g, h) proteins. (a) Truncated protein contains an alpha helix; RB1 dysfunction of this mutant type is due to frameshift and change in amino acids. (b) Truncated mutant; frameshift caused disrupted structure in this protein which is mostly loop. (c) Truncated form contains mostly native structure but the function has been lost upon frameshift. (d) This mutant protein contains mostly native structure but mutation and frameshift made the structure incomplete and caused RB1 dysfunction. (e) Native type. (f) This mutant has high similarity with the native structure but an alpha helix structure was transformed to a beta sheet, which indicates a major and significant RB1 structural variation in comparison with wild type. (g) and (h): Most of the wild-type RB1 protein exists but a frameshift resulted in protein dysfunction at the terminal residues.

Table 4 Novel mutations found in the present study and their Prosa Z-scores

\begin{tabular}{llr}
\hline No. & RB1 isoforms/mutants & Prosa Z-score \\
\hline 1 & p.Thr252AsnfsX11 & -6.37 \\
2 & p.Val288rmfsX1 & -7.85 \\
3 & p.E398D;fsX4 & -9.22 \\
4 & p.Leu512V;fsX8 & -11.34 \\
5 & p.Pro568LeufsX42 & -9.96 \\
6 & p.Arg611AspfsX11 & -10.75 \\
7 & p.Glu629AspfsX23 & -10.69 \\
& Wild RB1 protein (native) & -12.21 \\
\hline
\end{tabular}

detection rate was $49.1 \%$, with $66 \%$ in the heritable/ bilateral cases and $12 \%$ in the sporadic unilateral cases; published studies have reported rates ranging from 19 to $72 \% .3,12,14,15,17,25$ A recent study by Rushlow et al on 1024 patients ${ }^{17}$ reported $95 \%$ detection. However, only $10-12 \%$ of sporadic unilateral cases are caused by germline mutations. ${ }^{1}$ This variability in mutation detection rate might be explained by the different techniques employed and sample sizes recruited in these studies. We have already described MLPA and ARMS as rapid techniques for $R B 1$ mutation detection in a great number of RB cases. ${ }^{21-23}$ Limitations of the mutation detection methods likely largely account for the moderate mutation detection rate in this study. Another important reason for the lower rate of detection in this study for the bilateral RB $(66 \%)$ compared to some other publications is the shortage of budget. The study was mainly supported by ASHK charity rather than the payment by the patients and the health insurance companies. Recruiting more budgets for utilizing some other techniques including FISH, cytogenetic, quantitative multiplex PCR, testing for promoter mutations, and methylation studies, might enhance the power for detecting the gene alteration and/ or large rearrangements leading to retinoblastoma.

However, the authors may also not rule out the possible more roles of the gene modifiers in retinoblastoma in Iranian population. To increase the sensitivity of $R B 1$ mutation detection, a combination of two or more different methods has been recommended by The European Molecular Quality Network (EMQN). In turn, 

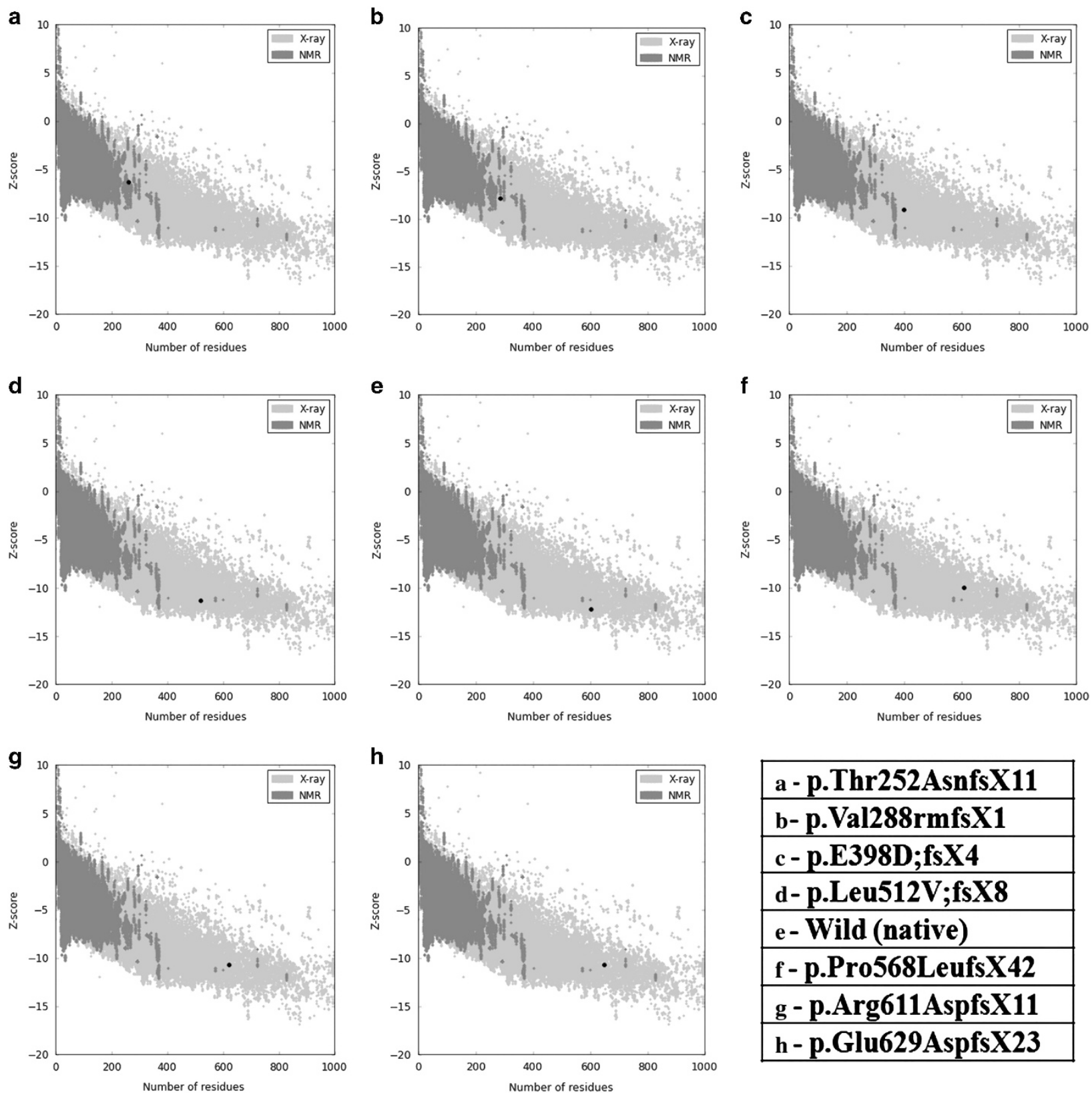

\begin{tabular}{|l|}
\hline a - p.Thr252AsnfsX11 \\
\hline b-p.Val288rmfsX1 \\
\hline c-p.E398D;fsX4 \\
\hline d-p.Leu512V;fsX8 \\
\hline e-Wild (native) \\
\hline f-p.Pro568LeufsX42 \\
\hline g- p.Arg611AspfsX11 \\
\hline h - p.Glu629AspfsX23 \\
\hline
\end{tabular}

Figure 2 Predicted X-Ray and NMR histograms for the wild-type and novel mutant forms of the RB1 proteins. Dark blue dots indicate the NMR ray quality, while the $x$ axis is the number of residues and the $y$ axis determines Prosa Z-score. a, b, c, d, f, g, and h indicate mutant histograms while e represent the native form of the protein. The mutant protein in $\mathrm{d}$ has the greatest similarity to the native (wild) structure. A full-colour version of this figure is available at EYE Journal Online.

our results in detection of $R B 1$ mutation are consistent with previous reports utilizing two different techniques, ${ }^{12,14,16,17}$ and are significantly higher than reported results utilizing only PCR sequencing. ${ }^{30,31}$ Therefore, mutation detection technologies that are sensitive to short and large rearrangements as well as epigenetic alterations might be employed to maximize the $R B 1$ detection rate. In our patients with no detected $R B 1$ mutation, 16 were unilateral sporadic cases, either bearing two somatic mutations or having an RB1 mutation in a mosaic state. In bilateral cases, the absence of a mutation can be explained either by RB1 inactivation through mutations in non-coding regions, by an epigenetic mechanism, and the role of some modifiers for RB1. Meanwhile, some cases of bilateral sporadic RB are carriers of somatic mosaicism and therefore not detectable in blood samples, ${ }^{14,17,25,32}$ while others may fail to be detected due to technological limitations.

The most prevalent $R B 1$ mutations reported in our study are nonsense and frameshift mutations; all of the 7 
novel mutations we identified were frameshifts. This novel pattern of $R B 1$ mutation may suggest the independency of the RB1 mutations causing RB in most cases. Nonsense and frameshift mutations mostly result in multifocal bilateral tumors; however intronic splice mutations showing low expressivity and incomplete penetrance due to minimal RB function ${ }^{16,33-36}$ that can be associated with less invasive disease.

The distribution of $R B 1$ mutations in this study showed no alterations in exons 3 and 22, most mutations were found in exons 10 and 19 followed by exons 8, 14, and 23 . Meanwhile, deletions of five exons (8, 10, 14, 19, and 23) (out of the twenty-seven) of RB1 were observed in $52 \%$ of retinoblastoma cases in this study, considering the 5 cases of the whole gene deletion. Considering functional importance of pocket A (exons 12-17) and pocket B (exons 20-23) domains of the RB protein, ${ }^{37} 27$ of 52 patients $(52 \%)$ had an alteration of the relevant 10 exons. However, RB1 exon 19 is the most prevalent for the occurrences of both overall and novel mutations, and it may indicate the presence of a hot spot for RB1 mutations in Iranian patients with retinoblastoma.

In this study, we investigated the effects of the 7 novel RB1 mutations on the function of the proteins. For $\mathrm{p}$. Thr252AsnfsX11, p.Val288rmfsX1 and p.E398D;fsX4, an immediate stop codon is located just after mutation. This makes a truncated protein with loss of function. For other mutations, the resultant protein is more similar to native form. The 3D structures of RB protein in all these 7 mutant types demonstrated a clear misfolding which is consistent with the pathogenesis of retinoblastoma.

In conclusion, although molecular analysis of the RB1 gene is technically difficult and its clinical implementation is complex, RB1 mutation screening allows for clinical prognosis of the disease and earlier management of patients with retinoblastoma. This analysis can also predict risk for families with germline mutations, which in turn may affect their family planning decision, and it may also result in reducing the number of unnecessary examinations under anesthesia for children in succeeding generations.

\section{Summary}

What was known before

- This is the most comprehensive report of RB1 screening in Iranian retinoblastoma patients.

- In this study distinctive mutational spectrum and some novel RB1 mutations have been observed, although it is comparable to those reported previously.

What this study adds

- Novel rare variations might be present in Iranian population, thus, RB1 genetic screening is crucial for prenatal diagnosis of retinoblastoma.

\section{Conflict of interest}

The authors declare no conflict of interest.

\section{Acknowledgements}

This work was supported by ASHK Corporation Institute (Tehran, Iran), The Eye Research Center at Rassoul Akram University Hospital (IUMS, Tehran, Iran), and The Intramural Research Program of the National Human Genome Research Institute. We greatly thank ASHK Institute for financial support of this study. We would also like to appreciate Professor Sue Povey for her critical reading and advice.

\section{References}

1 Vogel F. Genetics of retinoblastoma. Hum Genet 1979; 52(1): $1-54$.

2 Chintagumpala M, Chevez-Barrios P, Paysse EA, Plon SE, Hurwitz R. Retinoblastoma: review of current management. Oncologist 2007; 12(10): 1237-1246.

3 Abidi O, Knari S, Sefri H, Charif M, Senechal A, Hamel C et al. Mutational analysis of the RB1 gene in Moroccan patients with retinoblastoma. Mol Vis 2011; 17: 3541.

4 Knudson AG. Mutation and cancer: statistical study of retinoblastoma. Proc Natl Acad Sci USA 1971; 68(4): 820-823.

5 Moll AC, Imhof SM, Schouten-Van Meeteren AY, Kuik DJ, Hofman P, Boers M. Second primary tumors in hereditary retinoblastoma: a register-based study, 1945-1997: Is there an age effect on radiation-related risk? Ophthalmology 2001; 108(6): 1109-1114.

6 Wadayama B-I, Toguchida J, Shimizu T, Ishizaki K, Sasaki MS, Kotoura Y et al. Mutation spectrum of the retinoblastoma gene in osteosarcomas. Cancer Res 1994; 54(11): 3042-3048.

7 Comings DE. A general theory of carcinogenesis. Proc Natl Acad Sci USA 1973; 70(12): 3324-3328.

8 Harbour JW. Overview of rb gene mutations in patients with retinoblastoma: Implications for clinical genetic screening11The author has no proprietary interest in this study. Ophthalmology 1998; 105(8): 1442-1447.

9 Eng C, Li FP, Abramson DH, Ellsworth RM, Wong FL, Goldman MB et al. Mortality from second tumors among long-term survivors of retinoblastoma. J Natl Cancer Inst 1993; 85(14): 1121-1128.

10 Abouzeid H, Munier FL, Thonney F, Schorderet DF. Ten novel RB1 gene mutations in patients with retinoblastoma. Mol Vis 2007; 13: 1740-1745.

11 Blanquet V, Turleau C, Gross-Morand MS, SenamaudBeaufort C, Doz F, Besmond C. Spectrum of germline mutations in the RB1 gene: a study of 232 patients with hereditary and non hereditary retinoblastoma. Hum Mol Genet 1995; 4(3): 383-388.

12 Houdayer C, Gauthier-Villars M, Lauge A, Pages-Berhouet S, Dehainault C, Caux-Moncoutier V et al. Comprehensive screening for constitutional RB1 mutations by DHPLC and QMPSF. Hum Mutat 2004; 23(2): 193-202.

13 Lohmann DR. RB1 gene mutations in retinoblastoma. Hum Mutat 1999; 14(4): 283-288. 
14 Parsam VL, Kannabiran C, Honavar S, Vemuganti GK, Ali MJ. A comprehensive, sensitive and economical approach for the detection of mutations in the RB1 gene in retinoblastoma. J Genet 2009; 88(4): 517-527.

15 Pradhan MA, Ng Y, Strickland A, George PM, Raizis A, Warrington $\mathrm{J}$ et al. Role of genetic testing in retinoblastoma management at a tertiary referral centre. Clin Exp Ophthalmol 2010; 38(3): 231-236.

16 Richter S, Vandezande K, Chen N, Zhang K, Sutherland J, Anderson J et al. Sensitive and efficient detection of RB1 gene mutations enhances care for families with retinoblastoma. Am J Hum Genet 2003; 72(2): 253-269.

17 Rushlow D, Piovesan B, Zhang K, Prigoda-Lee NL, Marchong MN, Clark RD et al. Detection of mosaic RB1 mutations in families with retinoblastoma. Hum Mutat 2009; 30(5): 842-851.

18 Taylor M, Dehainault C, Desjardins L, Doz F, Levy C, Sastre $\mathrm{X}$ et al. Genotype-phenotype correlations in hereditary familial retinoblastoma. Hum Mutat 2007; 28(3): 284-293.

19 Castéra L, Sabbagh A, Dehainault C, Michaux D, MansuetLupo A, Patillon B et al. MDM2 as a modifier gene in retinoblastoma. J Natl Cancer Inst 2010; 102(23): 1805-1808.

20 Zhang J, Benavente CA, McEvoy J, Flores-Otero J, Ding L, Chen $\mathrm{X}$ et al. A novel retinoblastoma therapy from genomic and epigenetic analyses. Nature 2012; 481(7381): 329-334.

21 Saliminejad K, Behnam B, Akbari MT, Khorshid HR, Ghassemi F, Amoli FA et al. Rapid detection of RB1 recurrent mutations in retinoblastoma by ARMS-PCR. J Genet 2013; 92(2): e36-e40.

22 Ahani A, Akbari MT, Saliminejad K, Behnam B, Akhondi $\mathrm{MM}$, Vosoogh $\mathrm{P}$ et al. Screening for large rearrangements of the RB1 gene in Iranian patients with retinoblastoma using multiplex ligation-dependent probe amplification. Mol Vis 2013; 19: 454-462.

23 Ahani A, Behnam B, Khorshid HR, Akbari MT. RB1 gene mutations in Iranian patients with retinoblastoma: report of four novel mutations. Cancer Genet 2011; 204(6): 316-322.

24 Sambrook J, Fritsch EF, Maniatis T. Molecular Cloning. Cold Spring Harbor Laboratory Press New York: New York, USA, 1989.

25 Abouzeid H, Schorderet DF, Balmer A, Munier FL. Germline mutations in retinoma patients: relevance to low-penetrance and low-expressivity molecular basis. Mol Vis 2009; $\mathbf{1 5}$ : 771-777.

26 Kelley LA, Sternberg MJ. Protein structure prediction on the Web: a case study using the Phyre server. Nat Protoc 2009; 4(3): 363-371.

27 Wiederstein M, Sippl MJ. ProSA-web: interactive web service for the recognition of errors in three-dimensional structures of proteins. Nucleic Acids Res 2007; 35(suppl 2): W407-W410.

28 Karplus K. SAM-T08, HMM-based protein structure prediction. Nucleic Acids Res 2009; 37(suppl 2): W492-W497.

29 Eswar N, Webb B, Marti-Renom MA, Madhusudhan M, Eramian D, Shen My et al. Comparative protein structure modeling using Modeller. Curr Protoc Bioinformatics 2006; 54: 5.6.1-5.6.37.

30 Alonso J, Frayle H, Menendez I, Lopez A, Garcia-Miguel P, Abelairas J et al. Identification of 26 new constitutional RB1 gene mutations in Spanish, Colombian, and Cuban retinoblastoma patients. Hum Mutat 2005; 25(1): 99.

31 Choy KW, Pang CP, Yu CB, Wong HL, Ng JS, Fan DS et al. Loss of heterozygosity and mutations are the major mechanisms of RB1 gene inactivation in Chinese with sporadic retinoblastoma. Hum Mutat 2002; 20(5): 408.

32 Sampieri K, Hadjistilianou T, Mari F, Speciale C, Mencarelli MA, Cetta $\mathrm{F}$ et al. Mutational screening of the RB1 gene in Italian patients with retinoblastoma reveals 11 novel mutations. J Hum Genet 2006; 51(3): 209-216.

33 Harbour JW. Molecular basis of low-penetrance retinoblastoma. Arch Ophthalmol 2001; 119(11): 1699-1704.

34 Lohmann DR, Brandt B, Hopping W, Passarge E, Horsthemke B. The spectrum of RB1 germ-line mutations in hereditary retinoblastoma. Am J Hum Genet 1996; 58(5): 940-949.

35 Boerkoel CF, Exelbert R, Nicastri C, Nichols RC, Miller FW, Plotz $\mathrm{PH}$ et al. Leaky splicing mutation in the acid maltase gene is associated with delayed onset of glycogenosis type II. Am J Hum Genet 1995; 56(4): 887.

36 Lohmann DR, Gallie BL. Retinoblastoma: revisiting the model prototype of inherited cancer. Am J Med Genet C Semin Med Genet 2004; 129C(1): 23-28.

37 Dick FA. Structure-function analysis of the retinoblastoma tumor suppressor protein - is the whole a sum of its parts? Cell Div 2007; 2: 26 